\title{
Effect of Aqueous Soluted Nitriding Process on AISI 304 Austenitic Stainless Steel under Dry Sliding Conditions
}

\author{
M.Mamatha Gandhi ${ }^{*}$, J.Saranya ${ }^{2}, G . K e e r t h i$ Reddy ${ }^{3 *}, S$. Srikanth $^{3}, C h$. Keshav $^{4}, M$. Niranjan $^{4}, S . S o m e s h w a r ~ R a o^{4}$, \\ Ram Subbiah ${ }^{5}$ \\ ${ }^{1}$ Research Scholar, Singhania University, Jhunjhunu, Rajasthan 333515, India \\ ${ }^{2}$ Department of Basic sciences and Humanities, Gokaraju Rangaraju Institute of Engineering and Technology, Hyderabad 500090, \\ India \\ ${ }^{3}$ PG Students, Design for Manufacturing, Gokaraju Rangaraju Institute of Engineering and Technology, Hyderabad 500090, India \\ ${ }^{4}$ UG Students, Mechanical Engineering, Gokaraju Rangaraju Institute of Engineering and Technology, Hyderabad 500090, India \\ ${ }^{5}$ Faculty, Mechanical Engineering, Gokaraju Rangaraju Institute of Engineering and Technology, Hyderabad 500090, India
}

\begin{abstract}
AISI 304 stainless steel categorized under austenitic, has good resistance to corrosion and applicable for high resistance to pitting and stresses. But it has poor hardness, sterngth and resistance to wear. In order to overcome the above problem, various hardening techniques like nitriding, carburizing, carbonitriding, Cyaniding etc are preferred. In this work, aqueous soluted nitriding process is carried out to improve the surface hardness and wear resistance on AISI 304 specimens. Three specimens in cylindrical shape with a diameter of $10 \mathrm{~mm}$ and length $35 \mathrm{~mm}$ are treated with salt bath nitriding process for a time period of 45 minutes, 90 minutes, 120 minutes and named as SBN 1, SBN 2, SBN 3 respectively. One specimen is kept untreated to compare the results with treated specimens. After the heat treatment procedure is completed, pin on disc wear testing instrument was used to conduct a wear test at a constant speed and load. All the specimens were subjected to Scanning Electron Microscope test and the results were compared.
\end{abstract}

Keywords: Stainless steel, Surface hardness, Wear resistance, Wear test

\section{Introduction}

Stainless steel is a material that is widely utilized and commonly employed in corrosion-resistant applications. Stainless steels are collection of corrosion-resistant materials rather than a single material. Stainless steel is comprised with $12 \%$ chromium and does not corrode or stain, as the name implies [1]. Corrosion resistant steel is the name given to it in the aviation industry. Stainless steels are currently available in variety of grades, which can be chosen based on working conditions, climatic impact and other factors. Stainless steel are processed into sheets, plates, bars, wires and their applications are mainly in modern applications, Kitchen Utensils and Surgical Equipments [2-5].

Austenitic stainless steel usage has steadily expanded into new applications as they are relative in value and aesthetically preferred for base coated materials. Treated stainless steels have higher protection from chemical reaction and corrosion in various applications [6-9]. To utilize AISI 304 Stainless steel effectively in heavy load applications case hardening process are preferred. Case hardened stainless steel improves the wear resistance and hardness of the material [10].

Much of the research and development on stainless steel continues and generate novel ideas for improvement on the mechanical properties. Development of austenitic stainless steels with improved properties started since 1980s [11-13]. These materials are widely used for low temperature applications such as nuclear power plants, food processing industries, petrochemical industries etc. However, the use of this material on the surface is highly limited due to poor resistance to wear. Multiple surfaces treatments are available to improve tribological characteristics. Of the various surface hardening methods available, nitriding offers the advantage of high stability in dimension. The nitrogen content was added to stainless 
steel surface to improve hardness, strength and resistance to wear conventional nitriding methods [14-16].

\section{Experimental Procedure}

\subsection{Material Composition}

AISI 304 Austenitic stainless steel was chosen for this research work as shown in Figure 3. The composition of raw AISI 304 stainless steel were tested and found to be Chromium 17.99\%, Nickel 7.98\%, Carbon 0.03\%, Manganese $1.53 \%$, Phosphorous $0.012 \%$, Sulphur $0.008 \%$, Silicon $0.54 \%$ and remaining Iron.

\subsection{Tribological wear test}

AISI 304 stainless steels were chopped into 4 pieces with dimensions of diameter $10 \mathrm{~mm}$ and $35 \mathrm{~mm}$ length [17-20]. With the help of lathe machine, the edges of the specimens were sharpened to "U" shape. The specimens were subjected to salt-bath nitriding process for a time period of 45 minutes, as shown in Figure 4, 90 minutes as shown in Figure 5 and 120 minutes as shown in Figure 6 respectively. During the salt nitriding process the work pieces were bathed in the liquid shower containing potassium nitrate (KNO3) and sodium nitride salts $\left(\mathrm{Na}_{2} \mathrm{NO}_{3}\right)$ [21-23]. The entire processes were carried out in a muffle furnace and the specimens were treated to a temperature of $550-570^{\circ} \mathrm{C}$. The surfaces of the specimens were enriched with $\mathrm{Fe}_{3} \mathrm{~N}$ compounds. Before experimenting the samples were ultrasonically polished. The case depth and surface hardness were measured as shown in Table 1.

Table 1. Details of case depth obtained

\begin{tabular}{|c|c|}
\hline Specimen & Case Depth (Microns) \\
\hline Untreated Specimen & -- \\
\hline SBN 1 & 12 \\
\hline SBN 2 & 13.5 \\
\hline SBN 3 & 14.2 \\
\hline
\end{tabular}

Wear test were carried out on a pin on disc apparatus Model TE165SPOD, Made by Creator Industries shown in Figure 1. A disc with diameter $110 \mathrm{~mm}$ and with thickness of $10 \mathrm{~mm}$ subjected to salt bath nitriding process at saturated level were taken. A Load of $10 \mathrm{~N}$ (constant), Speed 600rpm (constant), Time 2minutess (constant) were the parameters chosen for conducting pin on disc wear test. During wear test the wear loss were noted. Weight loss is calculated by tracking the difference between a prewear and post-wear test.[23-25]

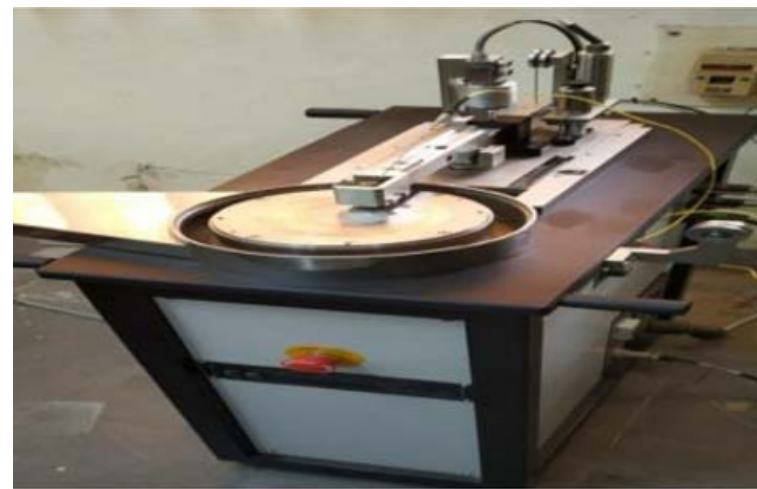

Fig. 1. Pin on Disc Apparatus

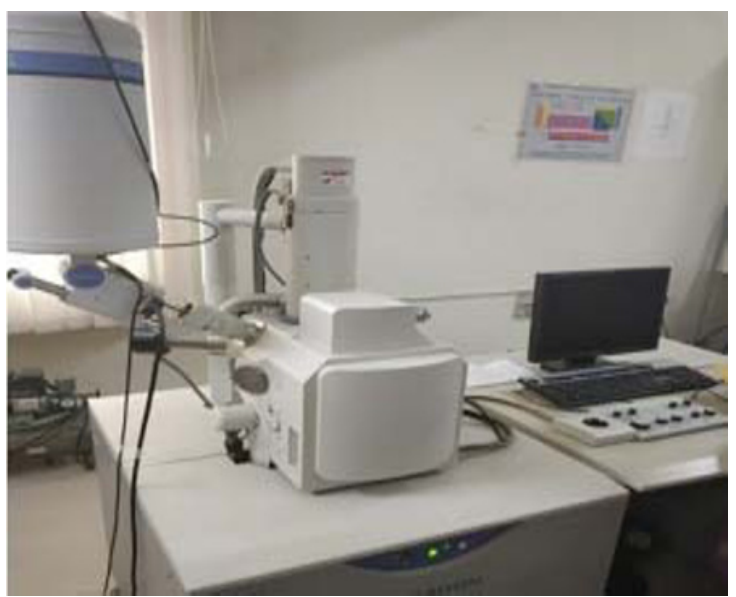

Fig. 2. Scanning Electron Microscope

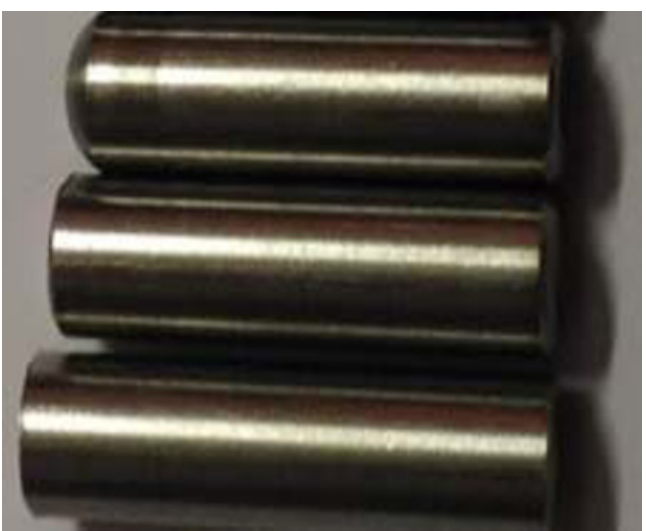

Fig. 3. AISI 304 Untreated Sample

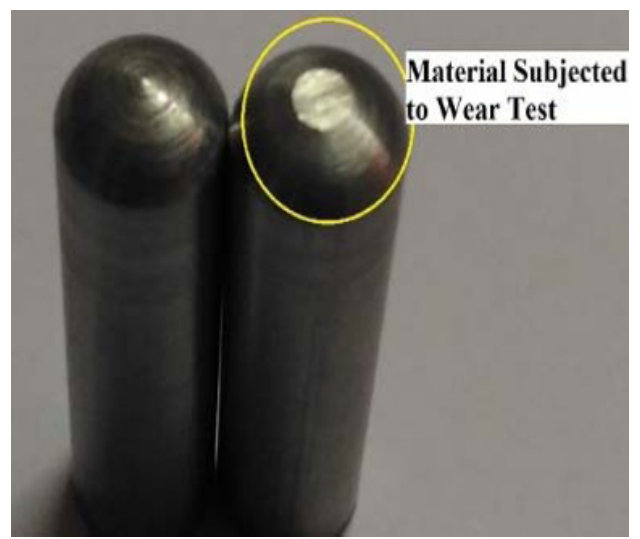

Fig. 4. SBN specimen treated to 45 Minutes 


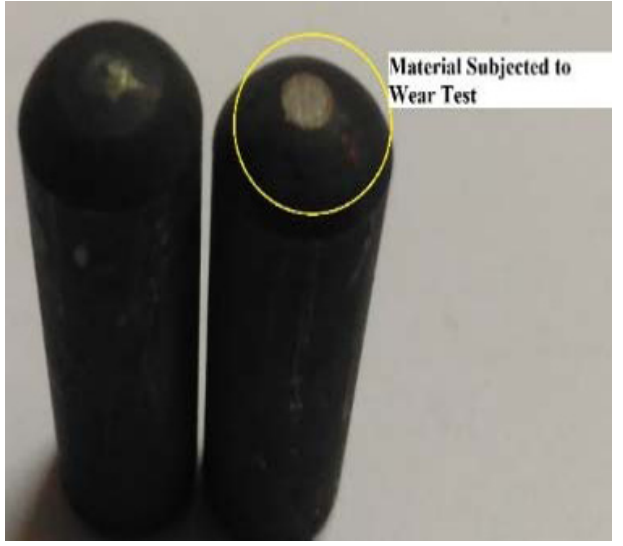

Fig. 5. SBN specimen treated to 90 Minutes

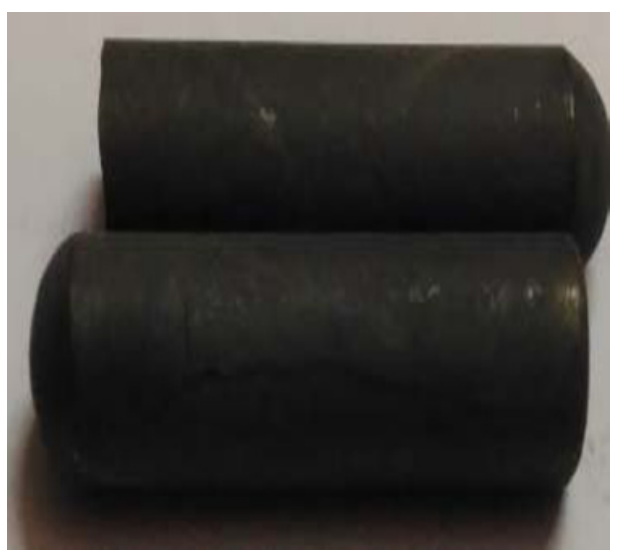

Fig. 6. SBN specimen treated to 120 Minutes

\section{Results and Discussion}

With the help of Rockwell hardness tester, all the specimens were tested for hardness by applying a load of $150 \mathrm{Kg}$ for duration of 20 Seconds. The hardness of the raw AISI 304 stainless steel was found to be $18 \mathrm{H}_{\mathrm{Rc}}$. The hardness of the specimens processed to 45 Minutes, 90 Minutes and 120 Minutes were found to be $19.5 \mathrm{H}_{\mathrm{Rc}}, 21.2$ $\mathrm{H}_{\mathrm{Rc}}, 22.9 \mathrm{H}_{\mathrm{Rc}}$. The microstructures of the specimens subjected to wear test were analyzed using a scanning electron microscope Genesis/Veritas Series model made by EmCrafts Co. Ltd as shown in Figure 2.

From the scanning electron microscope analysis surface morphology were carried out after wear test. The SEM images revealed the material peel off widely visible on the untreated specimen surface. From SEM images it was noted that, duration of nitriding increases from 45 to 120 minutes, the material peel off decreases. The depth of case increases along with the reduction in wear loss. It was found that the peel of material was low in the treated specimen.

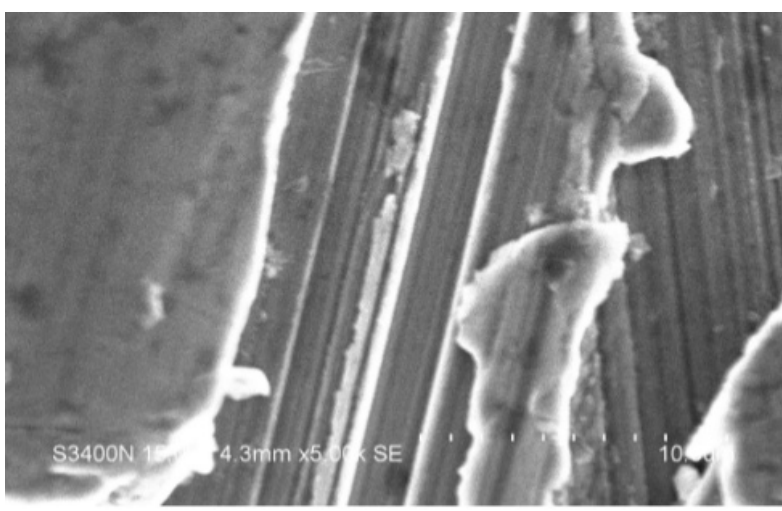

Fig. 7. SEM Image of Untreated AISI 304 Specimen

According to the results obtained it was found that, in untreated specimen the cracks are formed on the surface and also material peel were noted on a prominent place as Shown in Figure 7. This work analyzes the characteristics of the diffusion zone, where very small etches are visible in the compound layer. Dense layers on the compound zone were visualized with etching pits.

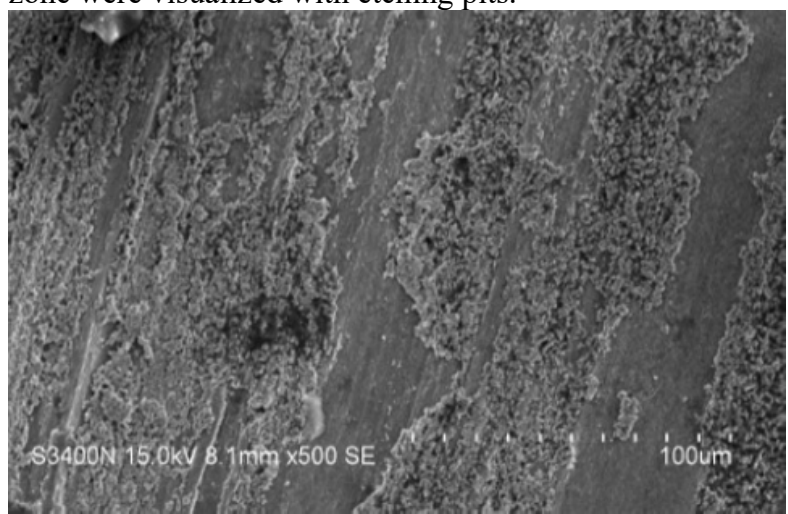

Fig. 8. SEM Image of SBN Specimen at 45 Minutes

From Figure 8, it was observed that the sample processed within 45 minutes has a coarse-grained structure of both carbon and nitrogen sedimentation. It is because of less treatment time. When a small amount of nitrogen gets diffused in the bonding zone, formation of iron nitride affects the resistance to wear on the substrate, while the diffusion zone increases the time for more nitride formation, restoring and improving the wear resistance.

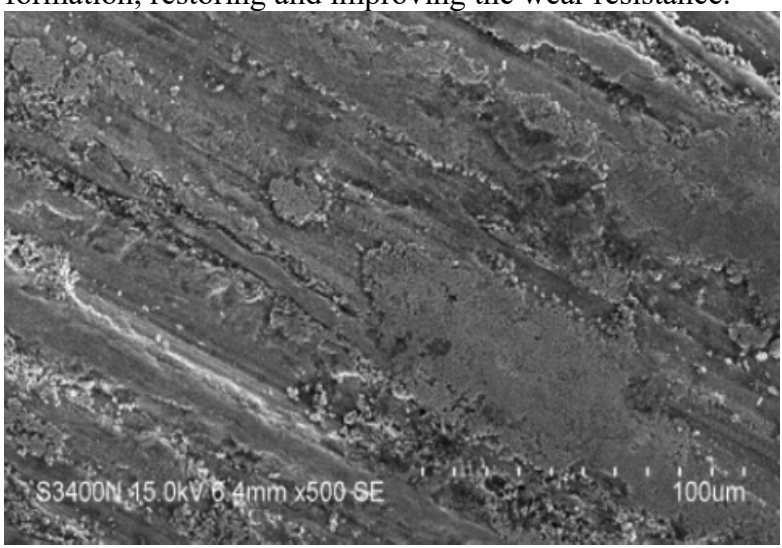

Fig. 9. SEM Image of SBN Specimen at 90 Minutes 
From the Figure 9, it was noted that on the surface of the treated specimen, a high hardened surface were formed, $\mathrm{w}$ protecting the material from external wear. A granular structure which is coarse in nature was observed in untreated specimen compared to treated specimen grain structure processed to 90 minutes and the cracks were minimized.

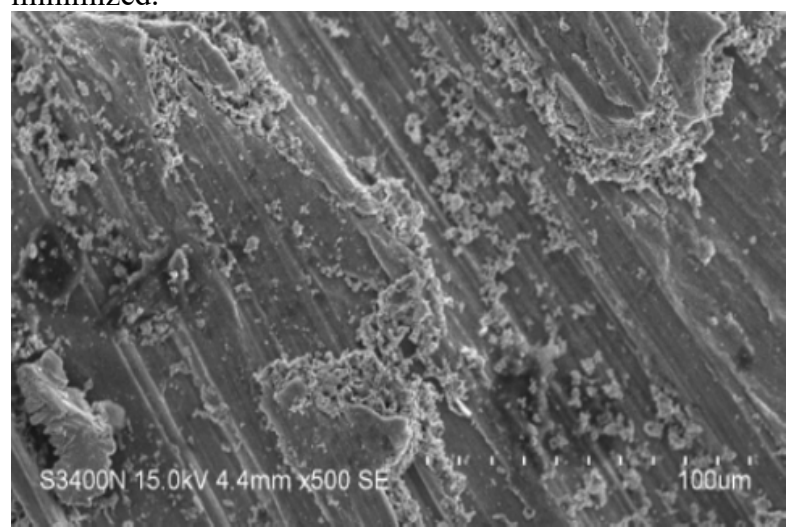

Fig. 10. SEM Image of SBN Specimen at 120 Minutes

From the Figure 10, it was noted that the specimen processed to 120 minutes, had a fine-grain structure with hardened layer comprising addition of nitrogen and carbon to AISI 304 SS. It was noticed that, cracks and peel of material were less when compared to other treated specimens. As the time of treatment increases, wear loss reduced during wear test. The diffusion of nitrogen and carbon atoms was high and provided noticeable resistance to wear. And for a specimen treated to 120 minutes, a compound layer with nitrogen and carbon atoms were high providing excellent resistance to wear. Finally, for a sample treated for $120 \mathrm{~min}$, the grain structure has become fine compared to the grain size of untreated specimen. Due to the correct proportion of nitrogen and carbon atoms, the surfaces of the specimen were provided with good resistance to wear. Sediments of carbon and nitrogen were distributed uniformly.

\section{Conclusion}

The wear behaviors of AISI 304 grade stainless steel were investigated in this research work under nitrided and nonnitrided conditions. The following are the main conclusions:

1. When the nitriding period increases from 45 to 120 minutes, the depth of case increases along with the reduction in wear loss. When compared to the other two nitrided samples, the 120 minute treated sample has strong wear resistance and case depth.

2. The untreated sample is compared with the properties of nitrided samples. The durability of the specimen treated to 120 Minutes was improved.

3. The third specimen with maximum hardness was found to be with the content of expanded austenite has provided excellent wear resistance.

\section{References}

1. F. Bottoli, M.S. Jellesen, T.L. Christiansen, G. Winther, M.A.J. Somers, App.Sur.Sci.J.E 431, 24 (2018).

2. N. Chen, G. Ma, W. Zhu, A. Godfrey, Z. Shen, G. Wu, X. Huang, Mat. Sci. Eng. A.J. E 759, 82 (2019).

3. M.G. Shahri, M. Salehi, S.R. Hosseini, M. Naderi, Surf. Coat Tech.J. E 310, 44 (2017).

4. Y.M. Wang, T. Voisin, J.T. McKeown, J. Ye, N.P. Calta, Z. Li, Z. Zeng, Y. Zhang, W. Chen, T.T. Roehling, R.T. Ott, M.K. Santala, P.J. Depond, M.J. Matthews, A. V.Hamza, T. Zhu, Nat. Mat.J. E 17, 63 (2018).

5. A.Popelka, I. Novák, M.A.S.A. Al-Maadeed, M. Ouederni, I. Krupa, Surf. Coat. Tech.J. E 335, 118 (2018)

6. Q. Chao, V. Cruz, S. Thomas, N. Birbilis, P. Collins, A. Taylor, P.D. Hodgson, D. Fabijanic, Scr. Mat.J. E 141, 94 (2017).

7. M.Mamatha Gandhi, Animesh Bain, P Rohith, R. Srilatha, Ram Subbiah, Structure and Topography Modifications of Treated AISI 316LN Stainless Steel Surfaces after Friction in Dry Sliding Contact by Case Hardening Process (EDP Sciences, Hyderabad, 2020)

8. K. Ramya Sree, G. Keerthi Reddy, K. Aishwarya, E. Nirmala Devi, Ram. Subbiah, New Insights of Wear Behavior Analysis on Low Temperature Treated AISI 253MA Stainless steel Material by Gas Nitriding Process (EDP Sciences, Hyderabad, 2020)

9. A Rohit Sai Krishna, B Vamshi Krishna, D Harshith, T Sashank, Ram Subbiah, Investigation of Mechanical Properties of AISI 316 Stainless Steel by Carbonitriding Process (EDP Sciences, Hyderabad, 2020)

10. Shivani Koppula, Aakula Rajkumar, Siram Hari Krishna, Reddi Sai Prudhvi, S. Aparna,Ram Subbiah, Improving the Mechanical Properties of AISI 2205 Duplex Stainless Steel by Cryogenic Treatment Process (EDP Sciences, Hyderabad, 2020)

11. Lakshmi Deepak Tadepalli, Ananda Mithra Gosala, Lokesh Kondamuru, Sai Chandra Bairi, A. Anitha Lakshmi, Ram Subbiah, Assessment of Properties on AISI430 Ferritic Stainless Steel by Nitriding process (EDP Sciences, Hyderabad, 2020)

12. Gandla Lakshmi Prasanna, G. Keerthi Reddy' Ram Subbiah, Evaluation of properties of AISI 431 Grade Stainless Steel by Vacuum Annealing Process (EDP Sciences, Hyderabad, 2020)

13. Gandla Lakshmi Prasanna, J Saranya, Ram Subbiah, Assessment of AISI 431Grade Stainless Steel properties by Vacuum Tempering Process (EDP Sciences, Hyderabad, 2020)

14. Manne Vamshi, J. Saranya, Ram Subbiah, Improvement of Characteristics of AISI 310 Grade Stainless Steel Material By Carburizing (EDP Sciences, Hyderabad, 2020)

15. ManneVamshi, AnimeshBain, M.Sreekanth, Ram Subbiah, Wear Characteristics of AISI 310 
Grade Stainless Steel Material by Carbonitriding Process (EDP Sciences, Hyderabad, 2020)

16. Ram.Subbiah, Md.Rahel, A.Sravika R.Ambika, A.Srujana, E.Navya, Investigation on Microstructure and Mechanical Properties of P91 Alloy Steel Treated With Normalizing Process - A Review (Materials Today: Proceedings, Hyderabad, 2019)

17. A. Rohit Sai Krishna, B. Vamshi Krishna, T. Sashank, D. Harshith, Ram Subbiah, Influence and assessment of mechanical properties on treated P91 steel with normalizing processes (Materials Today: Proceedings, Hyderabad, 2020)

18. K. Manjith Srinivas, S. Bharath, P. N. V. Krishna Chaitanya, M. Pramod, Ram Subbiah, Improving tribological properties of P91 steels through carburizing process (Materials Today: Proceedings, Hyderabad, 2020)

19. B.Chaitanya kumar, P.Sri Charan, Kanishkar Jayakumar, D.Alankrutha, G.Sindhu, Ram Subbiah, Assessment of wear properties on low temperature molten salt bath nitriding on austenitic stainless steel (Materials Today: Proceedings, Hyderabad, 2020)

20. T.LakshmiDeepak, G.Ananda Mithra, K. Lokesh, B. Sai Chandra, Ram Subbiah, Stability of expanded austenite by gas nitriding process on austenitic stainless steel material under low temperature conditions (Materials Today: Proceedings, Hyderabad, 2020)

21. Nirmala Devi, G.Chitra.S, Selvasekarapandian.S. Premalatha, M. Monisha, S. Saranya.J, Ionics.J.E 23, 2337 (2017)

22. Patel.S, Rana.R.S, Singh.S.K, Study on mechanical properties of environment friendly Aluminium E-waste Composite with Fly ash and E-glass fiber (Materials Today: Proceedings, Hyderabad, 2017)

23. Prasad.K.S, Gupta.A.K, Singh.Y, Singh.S.K, Materi Eng and Perform.J.E 25, 5411 (2016)

24. Ganesh.R, Subbiah.R, Chandrasekaran.K, Dry Sliding Wear Behavior of Powder Metallurgy Aluminium Matrix Composite (Materials Today: Proceedings, Hyderabad, 2015)

25. Dhanalaxmi.B, Apparao Naidu.G, Anuradha, K, Adaptive PSO based association rule mining technique for software defect classification using $A N N$ (Procedia Computer Science, Hyderabad, 2015) 